\title{
La Rioja y sus Repúblicas (1812 y 1815). Una experiencia local de construcción de poder
}

\author{
La Rioja and its Republics (1812 and 1815). A local power \\ building experience
}

Valentina Ayrolo

Universidad Nacional Mar del Plata

Argentina

\section{DOI: https://doi.org/10.25032/crh.v5i9.10}

Recibido: 9/05/2019

Aceptado:11/o8/2019

Resumen. El presente artículo tiene como propósito analizar las formas de ejercicio del poder ensayadas por una parte de la elite de La Rioja para seguir controlando el escenario local una vez desatado el proceso de independencia. Estudiamos la Diputación de Minas de Famatina y la declaración de independencia en 1815 en tanto experiencias que revelan la persistencia de una concepción múltiple de la soberanía que conllevó la posibilidad de experimentar formas de gobierno novedosas y dotó de aprendizajes y fundamentos a la vida política local. No se estudia la experiencia local en tanto parte del proceso de construcción del estado nacional, sino como un ensayo con sentido propio que puede leerse de forma autónoma.

Palabras clave: Pueblos, soberanía, La Rioja, Política

\begin{abstract}
The paper analyzes the ways of exercising power rehearsed by a part of the elite of La Rioja to continue controlling the local scenario once the process of independence is unleashed. We studied the Diputación de Minas de Famatina and the declaration of independence in 1815 as practices that reveal the persistence of a multiple conception of sovereignty that protected the possibility of testing innovative forms of government and provided learning and fundamentals to local political life. Local experience is not studied as part of the
\end{abstract}


process of building the national state, but as an essay with its own meaning that can be read autonomously.

Keywords: Peoples, sovereignty, La Rioja, Politics

\section{La Rioja y sus Repúblicas (1812 y 1815). Una experiencia local de construcción de poder ${ }^{1}$}

La Revolución de independencia que comienza en el Rio de la Plata en 1810, irrumpe en la sociedad riojana sacudiéndola e imponiéndole un nuevo marco de referencia que no termina de ser aprehendido ni por las elites, ni por los habitantes-vecinos-feligreses-ciudadanos. ${ }^{2}$

Para la década del diez del siglo XIX, La Rioja era una jurisdicción menor que contaba con un solo Cabildo en la ciudad del mismo nombre. Tuvo un Colegio Jesuita y tres conventos masculinos (mercedarios, dominicos y franciscanos). Pese a sus pretensiones de hidalguía en 1785 fue definida por el Gobernador Intendente Rafael de Sobre Monte como: «Pueblo pobre y corto, pues contiene solo dos mil doscientas ochenta y siete almas [...] la fábrica de las casas es miserable». 3 En lo administrativo, era una jurisdicción subalterna que dependía de la Gobernación Intendencia de Córdoba con cabecera en la ciudad del mismo nombre y en lo eclesiástico era Vicaria foránea de la diócesis con sede también en aquella ciudad. Si bien la vid había sido el primer fruto de su producción, para el momento que nos interesa, sin haber abandonado las características de una economía de subsistencia intentaba la diversificación de su producción incursionando en rubros diversos entre los cuales la minería prometía ser de importancia.

\footnotetext{
${ }^{1}$ Este trabajo forma parte de mi Proyecto Conicet (2018-2020). Agradezco los comentarios y observaciones recibidos de los evaluadores anónimos de este artículo.

${ }^{2}$ Sobre este particular consultar Cansanello, Oreste Carlos, «De súbditos a ciudadanos. Los pobladores rurales bonaerenses entre el Antiguo Régimen y la Modernidad», Boletín del Instituto de Historia Argentina y Americana «Dr. Emilio Ravignani, 1995, vol. 11, p. 113-140.

3 Citado por Ricardo Caillet Bois en su Introducción al Archivo del Brigadier General Juan Facundo Quiroga, Buenos Aires 1957, Tomo I, p. 10.
} 
El escaso desarrollo de la ciudad, así como lo recortado de su elenco burocrático administrativo tuvo su contrapeso en el progreso de entidades cuyo centro gravitacional estaba en el ámbito rural. Las encomiendas, pero sobre todo los mayorazgos constituidos alrededor de algunas pocas familias, tuvieron una relevancia especial en el paisaje social y político riojano. ${ }^{4}$ La diversidad de capitales que tenían disponibles las Familias o Casas, ${ }^{5}$ explica su amplio arco de intervención en el espacio público, así como el lugar que ocuparon en la memoria local. Esa potencialidad se vio traducida en una suerte de encarnación del poder $\mathrm{y}$, al mismo tiempo, en árbitros alternos del poder instituido. De modo simplificado podemos decir que dos Casas se disputaron la preeminencia local, Dávilas (Brizuela y Doria) ${ }^{6}$ y Ocampos. Detrás de ellos familiares sanguíneos, espirituales, arrimados y entenados configuraron estos actores colectivos ${ }^{7}$ que se disputaron el control del poder sobre La Rioja en las postrimerías del orden colonial.

El presente artículo analiza la coyuntura revolucionaria que puso a La Rioja frente a la urgencia de adecuar su funcionamiento político al nuevo marco

\footnotetext{
${ }^{4}$ En La Rioja hubo tres mayorazgos de los siete que se fundaron en el Rio de la Plata. Sobre este particular son insoslayables los trabajos de Roxana Boixados ver por ejemplo: «Familia, herencia e identidad. Las estrategias de reproducción de la elite en el rioja colonial (gobernación del Tucumán, siglo XVII y principios del XVIII)». Revista de la Asociación de Demografía Histórica. Madrid. ADEH, 2001, pp. 147-181 y «Herencia, descendencia y patrimonio en La Rioja colonial». Andes, Antropología e Historia, n. ${ }^{\circ}$ 8. Cepiha. Universidad Nacional de Salta, 1997, pp. 199-223.

${ }^{5}$ Entendemos las casas como familias extensas que incluían parientes sanguíneos, pero también, adoptivos, "arrimados» y espirituales. Las casas se identificaban con un apellido central e implicaban un patrimonio material, un conjunto de cargos burocráticos, una compleja trama de relaciones familiares y poder simbólico que podía verse concretado en la fundación de un mayorazgo. Las casas también pueden pensarse como organización tal como las define Halperin Donghi, Tulio Revolución y guerra, Buenos Aires, Fondo de Cultura Económica, 1972, p. 410. O como aquellas que estudia Gustavo Paz en tanto «verdaderas "redes" que funcionaban como una organización social no solo en el ámbito privado sino también en la esfera pública» PAZ, Gustavo «El gobierno de los «conspicuos»: familia y poder en Jujuy, 1853-1875» Hilda Sabato y Alberto Lettieri, La vida política en la Argentina del siglo XIX, Buenos Aires, Fondo de Cultura Económica, 2003, p. 223. Por último, las casas, en tanto entidades con más poder que la de un solo individuo, marcan el carácter corporativo de la sociedad presentándose como actores colectivos. Para una definición de este tipo de actor ver: Guerra, François-Xavier «Hacia una nueva historia política: actores sociales y actores políticos», Anuario IEHS, n. ${ }^{\circ} 4$, 1989, pp. 243$284 \mathrm{y}$ «De la política antigua a la política moderna: algunas proposiciones», Anuario IHES, $\mathrm{n}^{\circ}{ }^{18}$, 2003, pp. 201-212.

${ }^{6}$ El heredero del mayorazgo de Sañogasta Francisco Brizuela y Doria, haba nacido con el apellido Dávila y adoptado el Brizuela y Doria de su madre, Petrona, para poder heredar el vinculado.

${ }^{7}$ La definición de este tipo de actor puede verse en François-Xavier Guerra, «De la política antigua a la política moderna: algunas proposiciones», Anuario IHES, 2003, n. ${ }^{\circ}$ 18, pp. 201-212.
} 
ideológico que trajo aparejado la Independencia. Nuestro propósito es mostrar, por un lado, una de las experiencias más corrientes que abrió para el mundo hispano la invasión napoleónica a la Península, la entropía republicana. ${ }^{8}$ La estrategia ensayada por una parte de la elite de La Rioja para conservar su poder, desnuda la persistencia de un imaginario antiguo regimental y el fracaso, por lo menos parcial, de la implantación de nuevas concepciones sobre el origen y administración del poder. Además, alineado con este fenómeno y a través de la instauración de una Diputación de Minas, en Famatina, mostramos un ensayo «local» que revela la potencia de pensar «lo político» ${ }^{9} \sin$ proyectarlo en el Estado-nación, sino como experimentación en sí misma. Finalmente, nuestro estudio revela las derivas políticas que proponía la coyuntura. No solo por lo que hace a la novedosa forma de organización política implementada con la Diputación de Minas, en tanto parte del repertorio de posibilidades disponibles dentro de una lista amplia, sino también, por la reasunción de la soberanía y la declaración temprana de la independencia.

Sostenemos que las experiencias políticas que se dan en el contexto de lo que Halperin Donghi denominó el primer ciclo de la revolución (1810-1815), aunque efímeras muestran la persistencia de una concepción múltiple de la soberanía. Marca los límites concretos al éxito de los criterios modernos que sobre el poder habían intentado imponer los reyes de la dinastía borbona y también descubre las dificultades que tendrá que enfrentar el ala más radical de la revolución rioplatense en su intento por aplicar una lógica política regida por la idea de la soberanía única. ${ }^{10}$ En este punto, central a la construcción de un

\footnotetext{
${ }^{8}$ Esta noción usada por Aranda Pérez sintetiza el proceso por medio del cual las ciudades, en tanto Repúblicas, reclaman sus derechos de cara a la Vacatio Regis. El origen de la demanda se encuentra en la persistencia de un imaginario y una comprensión plural de la monarquía, pese las políticas de la dinastía Borbón. Aranda Pérez, Francisco «Un reino de repúblicas. Comunidades políticas ciudadano-oligárquicas y su representación en la Castilla Moderna» María Ángeles Faya Díaz (Coord.), Las ciudades españolas en la Edad Moderna: oligarquías urbanas y gobierno municipal, Oviedo, KRK ediciones, 2014, pp. 23-62.

${ }^{9}$ Rosanvallon, Pierre Por una historia conceptual de lo político. Buenos Aires, Fondo de Cultura Económica, 2003.

${ }^{10}$ Me parece importante destacar acá el llamado de atención que realiza Guerra en su libro Modernidad e Independencias cuando señala que no se debe olvidar la hostilidad compartida por revolucionarios y absolutistas hacia los cuerpos y sus privilegios dado su acuerdo ideológico respecto a la unidad de la soberanía. François-Xavier Guerra Modernidad e Independencias. Ciudad de México, Fondo de Cultura Económica, 2014 (Mapfre, 1992) p. 77.
} 
nuevo orden político, en el espacio rioplatense aún faltaba mucho por hacer para imponer los criterios liberales del poder. Las explicaciones que circulaban acerca del origen y gestión de la soberanía seguían mostrando la persistencia de la idea de pacto, sino con el rey con la revolución que encarnó su poder y luego lo reemplazó. En este marco nos preguntamos hasta qué punto podemos hablar de la vigencia de un nuevo lenguaje político y de unas prácticas novedosas o más bien de una impostura que se irá transformando, por efecto de la repetición en nuevos parámetros de organización.

Durante casi una década, el poder central tuvo que negociar incesantemente con los poderes locales la gobernabilidad del territorio que se pretendía dominar y mantener unificado. El gran desafío revolucionario fue evitar la fragmentación del espacio e impedir su independencia política. Cumplir este objetivo no fue fácil ya que pronto se le presentaron algunos obstáculos. Enfrentar lo que podríamos llamar primera disidencia resolvió a los revolucionarios a conformar, en 1810, un ejército que en el caso de la jurisdicción de Córdoba fue exitoso en su tarea de doblegar los apetitos autónomos de la elite local, aunque implicó el uso de la violencia. Pero también tuvo fracasos como el de Paraguay, a donde el ejercito comandado por Belgrano no pudo ni siquiera llegar, o la Banda Oriental donde con el correr del tiempo el desafío fue de naturaleza múltiple: enfrentar la resistencia realista de la ciudad, detener la expansión de «la otra revolución» ${ }^{11}$ y evitar la efectiva ocupación del espacio por parte de los portugueses.

Podríamos decir que si durante los cinco primeros años, 1810-1815, los revolucionarios tuvieron que convencer a las elites del Interior que el propósito de la revolución era preservar la soberanía del rey cautivo, en el ínterin, como señala Halperin, los herederos del antiguo régimen se convirtieron en sus adversarios. ${ }^{12} \mathrm{El}$ año de 1815 marca una primera crisis del orden revolucionario, la declaración de la Independencia un año después no cierra el ciclo de rupturas

\footnotetext{
${ }^{11}$ Tulio Halperin Donghi, Revolución y Guerra. Buenos Aires, Fondo de Cultura Económica, 1972, pp. 292-309.

${ }^{12}$ Tulio Halperin Donghi, De la Revolución de Independencia a la Confederación Rosista. Buenos Aires, Paidós, 1984, pp. 81-83.
} 
políticas, ni acalla las pretensiones de los Pueblos, la prueba más clara de esto es el estallido de soberanías de 1820.

El presente artículo se divide en tres partes. En la primera presentamos brevemente la situación de La Rioja al estallar la revolución de 1810 ya que importa ver el punto de inicio y la postura que sobre este gran acontecimiento hubo a nivel local. Conocer la forma en que La Rioja se incluye en la Revolución nos permite ponderar mejor como entiende su elite el discurrir político local. El segundo apartado se compone de dos secciones en las que nos ocupamos de analizar lo que denominamos republicas riojanas queriendo incluir en esta denominación las experiencias políticas de los años 1812 y 1815 .

\section{El alcance de la Revolución en La Rioja}

La invasión napoleónica a la península ibérica en 1808 inició, para ese conjunto político que era la Monarquía española, el período de sus independencias. ${ }^{13}$ Enterados de lo ocurrido en España, el Cabildo de Buenos Aires discutió entre los días 22 y 24 de mayo el futuro del virreinato. El día 25 se decidió conformar una Junta integrada por aquellos cuyo reconocimiento y legitimidad estaba dada por su breve, pero destacada actuación «política», en los sucesos de los últimos cuatro años en el Río de la Plata: la reconquista de la ciudad de Buenos Aires de manos inglesas en 1806 y la defensa de esta en 1807, la destitución del Virrey Sobre Monte y la constitución de un órgano de gobierno donde se destacaba la persona de Liniers, futuro virrey interino y héroe de la reconquista.

Las noticias de la Revolución en Buenos Aires fueron recibidas con distinto grado de entusiasmo en las ciudades del Virreinato. Las actas capitulares de la ciudad cabecera de la Gobernación Intendencia de Córdoba de los días que preceden y siguen al 25 de mayo muestran la falta de acuerdo entre los capitulares sobre cómo actuar respecto de los movimientos políticos de Buenos Aires.

\footnotetext{
${ }^{13}$ Guerra, Modernidad e Independencias...
} 
Algunos aceptaron la situación, con reparos, pero la mayoría permaneció atenta a posibles cambios. ${ }^{14}$

El 5 de junio de 1810, el Gobernador Intendente Gutiérrez de la Concha escribía al Cabildo de La Rioja una carta en la que le aseguraba que «las primeras personas de esta ciudad [se refiere a Córdoba]» habían declarado su lealtad a la Corona agregando que «Tampoco puedo dudar que la acendrada lealtad de V.S. le obligará a la misma entereza que ha manifestado el Cavildo Exmo. de Buenos Aires su honrado vecindario, la Ciudad de Montevideo, esta, y la de Salta, según se me anuncia...». ${ }^{5}$ Concha mencionaba que no todos estaban de acuerdo con el movimiento de Buenos Aires (incluso su Cabildo) dando a entender que lo ocurrido era solo un movimiento faccioso y por eso se debía actuar con cautela evitando pronunciarse.

La presión que el Gobernador Intendente y la elite cordobesa ejercieron sobre sus territorios subalternos para que no apoyasen la Revolución fue leída unos meses después por Juan Martin de Pueyrredón, Gobernador de Córdoba por un breve tiempo, como un acto opresivo que produjo la alucinación del pueblo de La Rioja. ${ }^{16}$ Las actas capitulares de las semanas que siguen a la llegada de noticias, desde Córdoba y Buenos Aires, sugieren que el sentimiento más persistente entre los riojanos era el de perplejidad. Esta sensación fue plasmada en una carta que el Cabildo de La Rioja dirigía a la Junta, el 28 de agosto. ${ }^{17}$ Para disolver la tensión que había producido el silencio riojano respecto de la revolución del 25 de mayo, el Cabildo se justificó diciendo no haber entendido que «el sabio sistema adoptado» era para «conservar los derechos del americano suelo $\mathrm{p}^{\mathrm{a}}$. nxo deseado y tierno soberano Fernando séptimo y sus legítimos sucesores». Agregaron que la confusión fue hija de su incapacidad para comprender la dimensión de semejante cambio por «la falta de Profesores letrados, la indefensa cituación y la

\footnotetext{
${ }^{14}$ Sobre la situación de Córdoba ver Valentina Ayrolo, «La ciudad cooptada. Refractarios revolucionarios en Córdoba del Tucumán (1810-1816)» Anuario IEHS, n. ${ }^{\circ}$ 26, 2011, pp. 11-29.

${ }^{15}$ Archivo General de la Nación (AGN) sala X Legajo 2-3-12.

${ }^{16}$ Carta de Pueyrredón a la Junta, fechada en Córdoba el 20 de octubre de 1810, AGN, X-2-3-12.

${ }^{17}$ AGN X 2-3-12, numerado como 159. Carta del 28 de agosto de 1810, firmado por los cabildantes: Andrés de Herrera y Sánchez, Francisco Xavier de la Vega y Castro, Lucas Ocampo y Castro y José Vicente Luis de Cabrera el resto de las citas sobre el asunto están en el mismo documento.
} 
incertidumbre de que en aquella época se hallaba poseida y el justo temor de presentir la violencia en que se hallaba comprometida» ante los rumores de una expedición que se dirigía a La Rioja. Para amortiguar el lento despertar riojano se informa que las buenas nuevas fueron comunicadas al Pueblo con «plausibles vivas, salvas, repiques y luminarias generales en la noche». Por fin, despejada cualquier duda se informa la elección de Mauricio Álvarez de Luna y Cárdenas, Bachiller practicante en Leyes como diputado a la Junta Grande que debía reunirse en Buenos Aires con representación de todas las Jurisdicciones.

Los meses que siguieron a esta carta no parecen haber sido de total calma. ${ }^{18}$ En noviembre, Cornelio Saavedra escribía al Cabildo riojano aprobando su conducta durante las "pasadas convulsiones de esa Provincia» ${ }^{19}$ a las que Pueyrredón se refiere como «la revolución en aquella ciudad». ${ }^{20}$ Aunque no sabemos de qué asunto se trató el dato nos sirve para conocer el estado de fermentación existente en la jurisdicción y comprender la urgencia que tenía la Junta constituida en Buenos Aires para que el Cabildo de La Rioja se pronunciase a favor de ella.

La situación que enfrentaba la Revolución en el Interior era diferente a los desafíos que le abría el Litoral. Allí, la elite de vieja raigambre colonial, un espacio acostumbrado a regirse por ritmos dilatados para la resolución de problemas y conflictos no encajaba con las urgencias revolucionarias. Halperin Donghi señala en su libro Revolución y Guerra, que en el Interior la Revolución se desarrolló dentro de la estabilidad y descartó la transformación del orden social imperante, en pos de lograr adhesión. ${ }^{21}$ Pero, si al principio pareció buena idea dejar a las elites locales decidir su destino, siempre y cuando se alinearan con Buenos Aires, seis años más tarde se llegó a la conclusión contraria. En parte como resultado de

\footnotetext{
${ }^{18}$ Un dato interesante es que el 30 de septiembre de 1810, Cornelio Saavedra escribía a Francisco Xavier Brizuela y Doria reconociendo su trabajo en el mineral de Famatina y agradeciéndole la contribución que había hecho del sueldo para dos soldados del cuerpo de arribeños por el término de un año lo que comunicó en carta del 24 de agosto de ese año. AGN X-29-9-1.

${ }^{19}$ Archivo Histórico de la Provincia de Córdoba (AHPC) Gobierno Caja/Tomo 32, Leg. 3: f. 354. Carta fechada en Buenos Aires, el 12 de noviembre de 1810.

${ }^{20}$ AGN, X 2-3-12. Carta del 2 de octubre de 1810, de Pueyrredón a la Junta. Numerada como 154.

${ }^{21}$ Halperin Donghi, Revolución y Guerra..., pp. 267-268
} 
las disputas intraelitarias que no solo enfrentaron a las Familias, sino que obligaron a los gobiernos centrales a depurar los bandos.

\section{Las «repúblicas» riojanas}

Mil ochocientos doce abre en La Rioja, la época de lo que podríamos caracterizar como entropía republicana. ${ }^{22}$ Pasada la primera fase de la tormenta revolucionaria en esta jurisdicción subalterna que contaba con un solo Cabildo y dos grupos que pugnaban por su control, se presentará una insólita propuesta para reestructurar el orden social y político. Un sector de la elite local, encabezado por los Brizuela y Doria, pretendió crear una nueva República con el propósito de lograr autonomía política para el control de una porción bien importante del territorio. La frustrada iniciativa se encadenó con una segunda oportunidad para ese mismo grupo. En 1815, La Rioja, en el marco de otros movimientos similares, declara su Independencia en la voz de su Gobernador Francisco Brizuela y Doria.

En este apartado analizaremos ambos momentos como parte de una experiencia política común a toda Hispanoamérica que abrió un proceso de aprendizaje, sedimentación y acomodamiento de estrategias de gestión del poder local hitos importantes para la construcción de la futura entidad provincial. ${ }^{23}$ Como ocurrió en todo el ex virreinato luego de la Revolución, también la elite riojana apeló a un discurso de corte republicano y «liberal» para justificar y explicar sus conductas políticas. Si en algunos lugares los comportamientos respondían a convicciones, en La Rioja fueron aparentemente una forma de ponerse a tono con los tiempos. Con todo, esta práctica fue instalando de manera gradual, y tal vez inesperadamente, discusiones sobre el origen y la legitimidad del poder, la representación y la ciudadanía. ${ }^{24}$

\footnotetext{
${ }^{22}$ Aranda Pérez, «Un reino de repúblicas...», p. 27.

${ }^{23}$ Sobre el tema de la construcción de la Provincia de La Rioja puede consultarse, Valentina Ayrolo, «Hacia la construcción de las Provincias: vínculos y obligaciones de Pueblo a Pueblo. Los casos de Córdoba y La Rioja 1815-1824» Revista de Historia del Derecho, Instituto de Investigaciones de Historia del Derecho, $n .{ }^{\circ}$ 52, julio-diciembre 2016, pp. 1-30.

${ }^{24}$ Sobre el tema de la ciudadanía y el orden político en el Río de la Plata las referencias bibliográficas son muchas, a modo de balance propongo la lectura de Elías Palti, «Orden político y ciudadanía. Debates en el liberalismo argentino del siglo XIX», Estudios interdisciplinarios de América Latina y el Caribe, vol. 5, n. ${ }^{\circ}$ 2, 2017.
} 
Una de las formas en la que se expresó la lógica política en la coyuntura posrevolucionaria estuvo ligada a las dinámicas e intereses familiares. Son estos los que explican, en parte, las estrategias grupales y personales que se desarrollaron en función de mantenerse en el poder. La reducción del conflicto riojano a «las querellas de Ocampos y Dávilas» ${ }^{25}$ como había señalado tempranamente Sarmiento, soslaya el verdadero origen de la discordia centrado, a mi entender, en los mecanismos puestos en juego para librar la pelea por el control de recursos, hombres y prerrogativas. Para ello, los grupos que administraban el poder se vieron precisados a reorientar sus lealtades, amistades y negocios en el sentido que dictaba la política extra provincial, incluso muchas veces de signo contrario a las prácticas habidas hasta entonces en La Rioja.

Corría el mes de julio de 1811 cuando la Junta de Buenos Aires escribía al hacendado de Famatina, Francisco Xavier Brizuela y Doria informándole que, pese a reunir las calidades requeridas para el cargo de Teniente Gobernador de La Rioja al que este Señor aspiraba, se lo consideraba «de mayor interés de ocupación en la Minería en que ha hecho tan felices ensayos...» ${ }^{26}$ que al frente de la administración riojana. Para ese cargo se elegía a Francisco Pantaleón Luna avecinado en Buenos Aires adonde había integrado el cuerpo de arribeños del que su tío Francisco Ortiz de Ocampo había sido comandante. ${ }^{27}$ Como era de suponer, la noticia del nombramiento no fue recibida con beneplácito por la Casa de los Brizuela y Doria ya que significaba un revés importante a sus pretensiones. ${ }^{28}$

\footnotetext{
${ }^{25}$ Domingo F. Sarmiento, Facundo. Buenos Aires, Losada, 1997 (1848), p. 128.

${ }^{26}$ AGN, X-21-9-1, Carta firmada por Cornelio Saavedra, 26 de julio de 1811. Posiblemente, estos hayan sido los mismos argumentos que el propio Brizuela utilizó para no asumir cargos en el cabildo de la ciudad en 1812. Cf. AGN, X-5-6-5, 17 de enero de 1812.

${ }^{27}$ El batallón de arribeños fue una unidad miliciana creada en 1806 con voluntarios de las provincias interiores del Virreinato del Río de la Plata, principalmente Córdoba, La Rioja, Tucumán y Catamarca, para defender Buenos Aires luego de la primera invasión inglesa al Río de la Plata en 1806.

${ }^{28}$ Como señalamos, Francisco Xavier Brizuela y Doria había nacido bajo el apellido Dávila, pero para poder heredar la hacienda de Sañogasta en calidad de mayorazgo cambió su apellido por el de su madre. Estaba casado con María Rosa del Moral uniendo su familia a una de las más importantes de la jurisdicción riojana. Armando Bazán, Historia de La Rioja. Buenos Aires, Plusultra, 1979, pp. 267-272; Marcelino Reyes, Bosquejo histórico de la Provincia de La Rioja. Buenos Aires, Cattáneo, 1913, pp. 48-61.
} 
Francisco Pantaleón Luna además de ser hijo de una Ortiz de Ocampo tenía propiedades e intereses en la región de Famatina. ${ }^{29}$ Había llegado a La Rioja iniciando el año de 1812, para reemplazar a su tío Domingo Ortiz de Ocampo, separado de su cargo de presidente de la Junta de gobierno local y comandante de Armas de la plaza de La Rioja por considerarse despótica y arbitraria su actuación. $3^{30}$

$\mathrm{Al}$ no haber obtenido el puesto deseado para Francisco Xavier, cabeza de la casa, los Brizuela y Doria buscaron una solución alternativa con el propósito de seguir controlando una gran parte de Famatina y algo de Guanadacol donde estaba ubicado el mayorazgo de San Sebastián del que Francisco Xavier era titular y propietario. ${ }^{31}$ Para conseguirlo establecieron una alianza con Santiago Carrera Gobernador Intendente de Córdoba, logrando que este los apoyara en la constitución de un poder paralelo e independiente del que tenía sede en La Rioja. $^{32}$

Esta construcción política se materializó a través de la figura de la Diputación Territorial de Minas una institución que funcionaba desde finales del siglo XVIII y que cobró importancia y destaque en La Rioja, entre 1812 y 1814. La diputación de minas - como veremos en el acápite que sigue- fue una fundación

\footnotetext{
${ }^{29}$ La jurisdicción riojana estaba constituida por cinco demarcaciones denominadas como parroquias o partidos. El de la ciudad, Arauco, Guandacol, Los Llanos y Famatina. Este último estaba ubicado en el oeste y una parte pequeña del norte riojano.

${ }^{30}$ Una abundante y detallada descripción de los cargos que los cabildantes Inocencio del Moral, José Vicente Luis de Cabrera, José Laureano de Molina y José Nicolás Carreño, presentaron contra Domingo Ortiz de Ocampo ocupa varias fojas en AGN, X-5-6-5.

${ }^{31}$ El vinculado de Sañogasta estaba ubicado entre ambos curatos. A este territorio se sumaba parte del de las Haciendas de otros Dávila haciendo de Famatina un lugar que, por motivos económicos, pero no solo, era clave para el poder.

${ }^{32}$ La historia de La Rioja está íntimamente ligada a la de Córdoba, desde su fundación en 1591. A partir de la creación de las gobernaciones intendencias en 1782 La Rioja será una tenencia de gobernación sujeta a Córdoba hasta 1820, con un breve impase en 1815. Por otro lado, desde 1806 fecha de la fundación de la diócesis de Córdoba, La Rioja será una de sus Vicarías foráneas. Esta dependencia durará hasta 1934 en que se funda el obispado de La Rioja. Sobre la historia de La Rioja puede verse: Dardo de la Vega Díaz, «La Rioja (1810-1862)» Historia de la Nación Argentina, Tomo X, Buenos Aires, 1947 y Armando Bazán, Historia de La Rioja.
} 
colonial creada en Nueva España para la administración de los asentamientos y distritos mineros. ${ }^{33}$

Considerando que en La Rioja solo hubo un cabildo, el de la ciudad, podríamos pensar que la autonomía arrogada por los Brizuela y Doria y su casa con la Diputación Territorial de Minas fue la expresión del anhelo de aquellos hombres de Famatina por un gobierno local propio.

\section{La Diputación de Famatina, «una nueva e independiente República» ${ }^{34}$}

La Diputación territorial de minas fue una institución colonial creada para la administración de los asentamientos y distritos mineros, en el marco de una nueva expansión minera en Nueva España. ${ }^{35}$ Según un viejo trabajo, este establecimiento podría haberse inspirado en la organización de las Rancherías de perlas fundadas en los primeros años de la colonia, aunque la actividad de los diputados que la integraban, en uno y otro caso, era muy diferente. ${ }^{6}$

Según José Enciso Contreras, quien estudia Zacatecas, las funciones de las diputaciones eran imprecisas. Habría sido una institución primordialmente política y organizativa, que representaba «a la comunidad política de propietarios mineros de características oligárquicas» y tendía a reproducir las funciones de los Cabildos. 37

\footnotetext{
${ }^{33}$ José Enciso Contreras, «La diputación de minas en Zacatecas en el siglo XvI», Memoria del X Congreso del Instituto Internacional de Historia del Derecho Indiano, Universidad Nacional Autónoma de México, 1995, p. 239.

${ }^{34}$ Este acápite está basado en un trabajo anterior Valentina Ayrolo, ««El sabor a soberanos» La experiencia de la diputación territorial de minas como espacio local de poder. Famatina, La Rioja del Tucumán, 1812» Secuencia, Ciudad de México, Instituto Mora, n. ${ }^{\circ}$ 86, mayo-agosto, 2013, pp. 53-74.

${ }^{35}$ Me interesa destacar la idea de diputación territorial que remite sin dudas a una concepción jurisdiccional del espacio y del poder. Recordemos que, como afirma Manuel Hespanha la distribución del poder político está relacionada, la mayor parte de las veces, con las condiciones materiales de la producción del poder, dónde población y espacio de dominio son determinantes. Manuel Hespanha, Vísperas del Leviatán: instituciones y poder político (Portugal, siglo XVII), Madrid, Taurus, 1989 , p. 58.

${ }^{36}$ Lloyd J. Mercham, «The Real Minas as a political Institution. A study as a frontier institution in Spanish Colonial America», HAHR, vol.7, n. ${ }^{\circ}$ 1, febrero, 1927, p. 63.

${ }^{37}$ Enciso Contreras, «La diputación de minas..., o. cit., pp. 440, 455 y 459.
} 
David Brading, por su parte, afirma que a partir de 1783 con la Real Ordenanza de Minería de Nueva España «las diputaciones mineras recibieron una extensa jurisdicción» y fue desde entonces que «tuvieron derechos sobre la propiedad $» .38$

Con todos estos elementos podemos pensar que los cambios introducidos para la minería en 1783 resultaron a todas luces originales ya que contravenían el origen ideológico reformista de los Borbón, reforzando, fortaleciendo y aumentando el poder de un grupo restringido de hombres, situación que no pasará inadvertida para los hombres de Famatina.

En el Alto Perú y Río de la Plata estas ordenanzas no se habrían aplicado. No obstante, existe un código elaborado por Pedro Vicente Cañete, que contempló la Real Ordenanza de 1783. En él, los mineros -entendidos como aquellos que habían descubierto alguna veta y por ello tenían derecho a explotarlas - «...debían integrar un Tribunal de minería en la capital de Potosí, formado por un director y tres Diputados generales, electivos ». ${ }^{39}$

En el esquema de las ordenanzas de 1783, existía un distrito minero llamado Real de Minas, que era donde las autoridades, además de ejercer las funciones de Gobierno, judiciales, fiscales y militares, debían aplicar las medidas conducentes al incremento de la producción de metales. Con frecuencia, el administrador era el mismo alcalde mayor de la provincia (Gobernación Intendencia) ya que allí se podían obtener las mayores ventajas económicas. ${ }^{40}$ Eduardo Martiré aclara que «En cada real de minas existían dos Diputados

\footnotetext{
${ }^{38}$ David Brading, Mineros y Comerciantes en el México borbónico (1763-181o), Ciudad de México, Fondo de Cultura Económica, [1971] 1983, p. 436. Por su parte, Ots Capdequí afirma que «Jurídicamente el dominio eminente de todas las minas seguía siendo de la corona; pero se permitió su beneficio a los particulares que las descubriesen y manifestasen, con arreglo a ciertas condiciones, que cambiaron según los tiempos, llegando incluso a sancionarse la existencia de minas de propiedad privada». José Ots Capdequí, M., Manual de Historia del derecho español en las Indias, Buenos Aires, Losada, 1945, p. 299

${ }^{39}$ Eduardo Martiré, Historia del derecho minero argentino, Buenos Aires, Perrot, 1979, p. 85.

${ }^{40}$ Sergio Ortega Noriega, Breve historia de Sinaloa, Ciudad de México, Fondo de Cultura Económica-El Colegio de México, 1999, Fideicomiso Historia de las Américas, «Serie Breves Historias de los Estados de la República», 1999.
} 
territoriales con igual número de substitutos». ${ }^{41}$ Estos diputados territoriales, «tenían facultades para resolver lo que no admitiese dilación, siempre que estuviesen situadas a más de veinte leguas del asiento del juez territorial del Partido. Los Diputados serían así mismo los síndicos procuradores de la minería en su territorio». ${ }^{42}$ Hasta aquí podemos ver la letra escrita en el código elaborado por Cañete. Pero veamos cómo se trasladó esto a la realidad rioplatense.

El mismo autor advierte que «en nuestro territorio nunca pudo constituirse el Tribunal de Minería, ni las diputaciones, a pesar de estar expresamente previsto en ese cuerpo» [se refiere a la ordenanza de 1783]. Lo mismo afirma María Concepción Gavira Márquez quien estudia el Alto Perú y Chile y sostiene, como el autor antes citado, que estas diputaciones no tuvieron realidad en esta región del continente. ${ }^{43}$ No obstante, contradiciendo lo normado, hemos podido comprobar que en la región que nos interesa se registraron por lo menos dos diputaciones territoriales de minas. Una en Jachal, San Juan, fundada en $1796^{44}$ y dependiente por aquel entonces de la Capitanía General de Chile y otra, más tardía, en Famatina, La Rioja, instaurada en 1812. Pese haber existido por lo menos dos diputaciones de minas no tenemos noticias de la existencia de un Tribunal de Minería para la región.

Enfocándonos en la diputación de Famatina, no se conoce que haya obtenido aprobación por parte de las correspondientes autoridades. La duda acerca de su legalidad fue planteada por el Teniente Gobernador Luna en 1812 apenas conoció las noticias de esa diputación:

... he mandado por repetido al Diputado Brizuela, me remita copia de Bando y providencia que autorizan su extraordinaria Diputación: ha tenido el arrojo de oficiarme en 29 de mayo y siete del corriente [junio] dudando de la jurisdicción de

\footnotetext{
${ }^{41}$ Martiré, «La autoridad minera en el código carolino de Pedro Vicente Cañete», Revista Chilena de Historia del Derecho, n. ${ }^{\circ}$ 6, vol. 14, 1970, p. 196

${ }^{42}$ Martiré, «La autoridad minera..., 196-197

${ }^{43}$ María Concepción Gavira Márquez, «Disciplina laboral y códigos mineros en los virreinatos del Río de la Plata y Nueva España a fines del periodo colonial», Relaciones, año XXVI, n. ${ }^{\circ} 102$, Colegio de Michoacán, Zamora, 2005, pp. 201-232.

${ }^{44}$ AGN, IX-24-3-5.
}

- 248 - Claves. Revista de Historia, Vol. 5, No 9 (julio - diciembre 2019) ISSN 2393-6584 
este Gov.no sobre su individuo y ocultándome maliciosamente aquellos recaudos, que deben probar sus excesos, o buen comportamiento... ${ }^{45}$

El estilo sui generis de la Diputación de Famatina dificulta pensar en su marco legal, aunque, por los informes hallados en los archivos, lo más probable es que se hayan tomado como referencia las ordenanzas de Nueva España. En cambio, resulta evidente que la creación de las diputaciones territoriales implicó que un número limitado de hombres se adjudicase poder para resolver temas vinculados a las minas del territorio del que «eran» o se decían representantes, quedando habilitados para el manejo de recursos económicos, sociales y políticos.

En la legislación ideada por de Cañete «la autoridad minera era complicada. Los funcionarios encontraban superpuestas sus atribuciones, sobre todo en los casos de gobierno...». ${ }^{46}$ Esto ocurría porque al adecuar la Ordenanza de Nueva España al Perú y Río de la Plata, hubo que combinar dos formas diferentes de concepción y acción del aparato administrativo.

La superposición de potestades y atribuciones produjo muchos de los problemas jurisdiccionales gracias a los cuales hoy tenemos conocimiento sobre este tema. Así, un conflicto habido en 1799 entre los jueces pedáneos ${ }^{47}$ de Jachal, San Juan, y los dos diputados territoriales de minas nos permite observar cómo los mencionados diputados actuaban de forma autónoma prescindiendo de la estructura administrativa dentro de la cual fueron pensados. ${ }^{48}$ En el documento antedicho se advierte que la creación de la diputación de minas fue irregular y no

\footnotetext{
${ }^{45}$ AGN, 29-9-1, Carta de Luna del 20 de junio de 1812 dirigida al Gobierno central. El resaltado me pertenece.

${ }^{46}$ Martiré, 199.

${ }^{47}$ Se llamaban jueces pedáneos aquellos que cumplían las mismas funciones que los alcaldes de hermandad durante la época colonial. Las pedanías eran las jurisdicciones más pequeñas en las que se dividía un partido o curato en las regiones de Córdoba, La Rioja y San Juan por lo menos.

${ }^{48}$ Cabe mencionar que hay cuatro artículos que refieren a los Diputados Territoriales de minas en la «Real Orden de 1783 sobre la explotación...» dada en Santiago, 1787. Estos son los artículos: $12,13,16$ y el 28 . Al respecto se señalan las dificultades existentes para constituir la estructura de la administración minera según la ordenanza de Nuevo México, se mencionan sus actividades que remiten a funciones de vigilancia y policía y por otro lado en el artículo 13 se aclara que dada la escasez de idóneos en vez de nombrarse dos diputados - como se indica en la Ordenanza de 1783, art.8- se nombraría solo uno con dos substitutos en vez de cuatro como lo indicaba el artículo 9 de la Real Orden de 1783.
} 
siguió ninguno de los pasos legales pensados a tal fin. Es por lo que se solicita eliminar la diputación:

Las precitadas ordenanzas [se refiere a las de Nueva España de 1783] aunque se comunicaron para su observancia en esta América en lo que fuesen aceptables, no han puesto hasta ahora en excusión en este virreinato, pues ni se ha erigido el tribunal general de Minería, ni los juzgados de alzada [...] corresponde se haga cesar inmediatamente la expresada diputación... ${ }^{49}$

En consecuencia y por ello, resulta muy difícil evaluar argumentos y posiciones cotejando o contraponiéndolas con la reglamentación vigente. Si bien la norma era la Real Ordenanza de 1783, cuyo alcance estaba limitado por la situación local, a partir de algunas alusiones podría pensarse que esta normativa coexistía con otras como las de Toledo (1573), la adaptación realizada para Chile en 1788 y el Código Carolino.50 No obstante, dado que la legislación de Nueva España se había adoptado en la Capitanía General de Chile podría ser que se la considerara apta para el gobierno de las minas de Famatina. ${ }^{51}$ Como vemos se puede afirmar con Martiré que en el Virreinato del Río de la Plata no queda claro qué legislación minera se aplicaba. ${ }^{52}$

Todo lo mencionado antes, nos induce a considerar que en el caso que estudiamos las prácticas son más reveladoras que la norma. Luego de esta breve introducción necesaria, vamos a analizar la diputación de minas de Famatina.

\footnotetext{
${ }^{49}$ AGN, IX 24-3-5, el resaltado es mío. Según el código carolino existiría una figura denominada alcalde mayor de Minas que, dependiente del virrey, debía cumplir funciones de juez territorial de su intendencia [en este caso Jáchal] y de superintendente de Minas. (Martiré, 196). Por otro lado, atendiendo a las modificaciones realizadas en 1787 en Chile, las jurisdicciones mineras se erigiría un administrador general de Minas que concentraría «todas las facultades, fueros y privilegios» era este el encargado durante sus visitas de elegir a los diputados» (arts. 11 y 12).

${ }^{50}$ En una carta a las autoridades Caballero, comisionado director del mineral de Famatina, les decía que «para que progrese rápidamente el reino mineral de su mundo, es preciso se adopten en él las reglas metódicas sólidamente establecidas en el Reino de México...» AGN, X-3-13.

${ }^{51}$ Sobre su uso en Chile ver: Dougnac Rodríguez, Antonio, «Proyección de las ordenanzas de minería de nueva España en Chile (1787-1874)», Revista de Estudios Histórico-Jurídicos, n. ${ }^{\circ}$ 21, 1999.

${ }^{52}$ Según este autor: «Las Ordenanzas de Toledo se aplicaron incluso en el virreinato de Nueva España. Así lo considera Francisco Javier de Gamboa en sus Comentarios a las Ordenanzas de Minas, señalando que estas leyes "son igualmente útiles para aprovecharse de algunos puntos y noticias, que no se hallan en las Ordenanzas de el nuevo Quaderno, ni en las leyes de la Recopilación de Indias: por ser muy ajustado a razón, que en los puntos omitidos se atienda la ley, o costumbre de la Provincia más cercana, especialmente fraternizando tanto las del Perú y Nueva España”» (Martiré, Eduardo, Historia del derecho minero..., pp. 35-36.
} 
Sabemos que por lo menos desde 1786 había un gremio de mineros en Famatina, pero nada se menciona en esos papeles sobre la existencia de una Diputación. En 1809 había 36 mineros ${ }^{53}$ según un relevamiento realizado por el juez de minas José Víctor Gordillo, ${ }^{54}$ y en 1812 cerca de $34^{55}$ que para 1823 se habrían reducido a once. Respecto a las autoridades en 1812, fue juez de minas Anastacio Zeballos y la función de juez veedor de minas la desempeñó Januario Güiraldes. ${ }^{56}$ En ese año de 1812, sí se registran cuatro diputados territoriales que se alternan en las funciones: Francisco-Xavier Brizuela y Doria, José Manuel Derqui, Ramón Brizuela y Doria y Pedro Antonio Gordillo, todos pertenecían o estaban vinculados a la Casa de los Brizuela y Doria. ${ }^{57}$

Como se recordará, una de las estrategias económicas de la Revolución para paliar la suspensión de los ingresos de plata de Potosí, había sido la reactivación del trabajo de las minas. En 1810 la Junta de gobierno comisionó a José María Caballero para inspeccionar y administrar «el mineral» de Famatina. Pero, pese a tener órdenes y poderes emanados de la Junta, Caballero no pudo cumplir su cometido porque, según informó a las autoridades centrales, el juez comisionado Gordillo y los comandantes de armas del mineral se resistían a obedecerle..$^{58}$

\footnotetext{
${ }^{53}$ Archivo Histórico de la Provincia de Córdoba (AHPC) Fondo Gobierno, caja/tomo 31, leg. 7. Informe de José Víctor Gordillo, juez de minas. Interesa señalar que en este informe Gordillo dice que en su empadronamiento considerará a todos los que trabajan las minas «entendiéndose de aquellos que tienen sus trabajos en corrientes» pese a que en el «art. 2, titulo 2 de las Ordenanzas» se define como mineros a aquellos que tienen trabajos corrientes en las minas por lo menos desde hace un año.

${ }^{54}$ Permanece en su empleo hasta el 30 de enero de 1810 en que llega a La Rioja, José María Caballero elegido por el virrey Cisneros como juez veedor de minas. AHPC, Gobierno, Tomo/caja 32 , leg 25 bis.

${ }^{55}$ AGN, X 5-6-5.

${ }^{56}$ Un documento del 14 de agosto de 1812 se refiere a Zeballos como «imaginario juez de minas». AGN, X-5-6-5, X-21-9-1, X-5-3-5. En una carta del 16 de agosto Güiraldes figura como juez de minas Colección Documental «Mons. Dr. Pablo Cabrera», Sección Americanistas, Biblioteca Central de la Facultad de Filosofía y Humanidades «Elma Kohlmeyer de Estrabou» ex Instituto de Estudios Americanistas, Universidad Nacional de Córdoba, (en adelante IEA) documento n. ${ }^{\circ}$ 3850 .

${ }^{57}$ La diputación pasó entonces a manos de Ramón Brizuela y Doria (hijo de Francisco Xavier, quien también se fuga más tarde cuando la conflictividad había aumentado) y de Pedro Antonio Gordillo en calidad de interino, quien fue elegido por Ramón Brizuela y Doria.

${ }^{58}$ AGN, X-2-3-13. Según el historiador Ricardo Caillet-Bois, fue hacia 1804 que se iniciaron los trabajos metódicos en las minas.
} 
Como dijimos Francisco Pantaleón de Luna intentó desde su llegada a La Rioja ejercer jurisdicción sobre las minas. Para ello comenzó eligiendo un nuevo administrador de la Caja de Rescate del mineral y solicitó que se le envíe el archivo de la diputación para tomar conocimiento de sus movimientos. Las decisiones de Luna, fueron objetadas por el Gobernador Intendente de Córdoba, Santiago Carrera, quien amonestó al Teniente Gobernador riojano por su intervención en Famatina. Las dificultades entre Luna y el Gobernador Carrera se trasparentaron en una guerra epistolar que fue coronada con la decisión de Luna de establecer comunicación directa con el gobierno central, ya que consideraba al de Córdoba - del que era subalterno- en connivencia con los Brizuela y Doria.

En junio de 1813, Luna explica a la Junta de Buenos Aires su versión de los hechos diciendo que la causa que le impedía ejercer jurisdicción sobre Famatina eran los intereses y proceder de los Rodríguez, ${ }^{59}$ quienes estaban representados por Derqui y Brizuela y Doria. Y seguía:

\begin{abstract}
Poco antes de nuestra gloriosa Revolución el asesor $\mathrm{D}^{\mathrm{n}}$. Victorino Rodríguez casado en la familia de Chilecito, [estaba casado con Felipa Antonia Tagle, riojana], hacienda de los Gordillo enlazado por matrimonio con los Sanrromanes, Brizuelas y Dávila de Sañogasta inmediatos al mineral, y casi todos o los más con interés en el cerro: hallándose de Visitador por el Gobernador Concha en el mismo Chilecito, desmembrando la caxa y magistrados de esta República, llevó a su Casa el fondo de rescates, poniendo administrador a $\mathrm{D}^{\mathrm{n}}$ Bernabé González Bueno con manejo de más de 50 ooo pesos, la su delegación en manos de $\mathrm{D}^{\mathrm{n}}$ Victor Gordillo su primo hermano quitando el Comisionado al su delegado de esta ciudad puso también poco después a su influjo al europeo $\mathrm{D}^{\mathrm{n}}$ Manuel Derqui casado con su sobrina carnal suya de comandante de armas de dicho mineral, y desnudó a este Pueblo, unido con dicho Concha, de sus derechos sementales; habiéndose fundado esta República a expectación del famoso Cerro de Famatina, comprendido en su inmediato territorio. ${ }^{60}$
\end{abstract}

La descripción que nos legó Luna muestra que los espacios más importantes de la administración de Famatina estaban ocupados, antes del año de 1812, por la Familia de Chilecito como la denomina. Indica, además, las alianzas matrimoniales y los arreglos que finalmente ubicaron a todos en los

\footnotetext{
${ }^{59}$ Se refiere al cordobés Victorino Rodríguez había sido Gobernador Intendente de Córdoba por un breve tiempo mientras arribaba a su destino Gutiérrez de la Concha.

${ }^{60}$ Mensaje dirigido al gobierno de Buenos Aires el 19 de junio de 1813, AGN, X-5-6-5. El resaltado me pertenece.
} 
lugares más importantes de la jurisdicción del mineral. Según un relato que consta en el fondo que guarda los papeles referidos a este asunto:

El 25 de abril último [de 1812], si no me engaño, [Derqui], fundó la diputación se hizo jurar por los Mineros, como soberano, y los que jamás han sido, ni son, con el fin de aumentar el gremio a los ojos de su favorito el Gobernador [de Córdoba] sujetó a sí a los jueces pedáneos presentes, y los obligó también a jurar obediencia... ${ }^{61}$

En este intercambio epistolar, también figura cómo se instaló la Diputación territorial de minas desnudando el mecanismo de elección de los representantes:

Por una Junta tumultuosa, convocada sin autoridad, dentro del mismo Chilecito y sin asistencia de los más, y principales mineros, se eligieron aquellos Diputados recíprocamente, concurriendo a ello hermanos, primos hermanos, e inmediatos parientes, y en ocasión que Derqui se hallaba allí desterrado por enemigo de la Patria [...] sorprendido el gobernador de Córdoba confirmó esta Diputación... ${ }^{62}$

Inmediatamente después de esta elección, sigue el relato, se hicieron jurar «obediencia y fidelidad» por los particulares, los del gremio, «los meros arrieros que no eran del gremio y forzados a ejercitarse en un empleo que aborrecían y no les tenía en cuenta», ${ }^{63} \mathrm{y}$ hasta «los jueces pedáneos del territorio, celebrando este acto con licencia de juegos prohibidos en el populacho». ${ }^{64} \mathrm{El}$ informe que sigue a esta descripción muestra que los diputados territoriales habrían accionado para sustraer a la población de la obligación de enrolarse en el ejército con la excusa del trabajo en el mineral. Como corolario, a partir de esta Diputación, «sin exemplar en todo el Reyno» - como observa Luna-, se habría intentado formar una jurisdicción separada de la de la ciudad de La Rioja dejando sin potestad sobre Famatina, al Teniente Gobernador.

Aunque Luna había querido salvar la responsabilidad del Gobernador de Córdoba, indicando que su aceptación de semejante proceder era consecuencia

\footnotetext{
${ }^{61}$ AGN, X-21-1-9, 17 de agosto de 1812, documento producido por el T. Gobernador Luna. El resaltado me pertenece.

${ }^{62}$ AGN, X-21-9-1. La Rioja, 20 de junio de 1812.

${ }^{63}$ El 20 junio de 1812, el Teniente de Gobernador Luna había denunciado este tipo de desorden diciendo: «Son tantos los atentados y tropelías cometidas por la Diputación de Minas contra los particulares ciudadanos, contra los milicianos, contra los Indios mucho mas y aun contra los mismos Magistrados del territorio...». Esta y otras denuncias se inician el 8 de junio de 1812 y están en AGN, X-21-1-9. Volveremos sobre el tema.
}

${ }^{64}$ AGN, X-21-9-1. La Rioja, 20 de junio de 1812. 
de que había sido tomado por sorpresa, el Gobernador Santiago Carrera redacta un documento en el que dejaba aclarados los límites del poder de cada grupo y su posición al respecto. Según este escrito, la autoridad del Teniente Gobernador sobre la diputación era nula y debía observarse, como hasta ese momento, la legislación dada para Nueva España.

El apoyo brindado por el Gobernador de Córdoba a los diputados territoriales de Famatina se retrata en la comunicación que Carrera envió al diputado Ramón Brizuela y Doria, elegido el 26 de junio de 1812, donde le informaba que el Teniente Gobernador - Luna- no podía interferir en los asuntos del Mineral ni disponer de las personas que allí residían ya que era de estricta competencia de la Diputación-. También en esa carta ordenaba «que los jueces pedáneos quedan sujetos a los diputados territoriales en los términos declarados - motivo por el cual «no operaban, sino con consulta, y mandamiento de los diputados»- que el teniente gobernador de La Rioja no debe tomar conocimiento en causa alguna de minas sean de los diputados sus parientes, o cualesquiera otro individuo». ${ }^{65}$

Fue en reacción a semejantes medidas que Luna escribió una extensa presentación ante el gobierno central el 17 de agosto de ese mismo año. En ella acusaba al Gobernador de Córdoba, Carrera, de beneficiar a los Diputados en su contra siendo que él había sido elegido por el gobierno central. Pero además agregaba que Carrera: «fomenta su ambición [la de Derqui y los Brizuela y Doria] [...] levanta una nueva e independiente República dentro del territorio de mi mando para que me insulte con libertad, desobedezca mis providencias...», ${ }^{66}$ condensando con claridad uno de los objetivos más evidentes de los Brizuela y

\footnotetext{
${ }^{65}$ AGN, X-5-6-5. Córdoba, 26 de junio de 1812. El resaltado me pertenece Estas disposiciones son la respuesta a un comunicado del Gobernador Luna al diputado de minas Brizuela y Doria. AGN, 21-9-1, 15 de junio de 1812. Recordemos que, como mencionamos antes, según la legislación de Nueva España la diputación tenía potestad para resolver aquellos asuntos urgentes «siempre que estuviesen situadas a más de veinte leguas del asiento del juez territorial del Partido». Este claramente no es el caso de Famatina donde se somete al juez pedáneo a la égida jurisdiccional de la diputación

${ }^{66}$ AGN, X-21-1-9, 17 de agosto de 1812, documento producido por el Teniente Gobernador Luna. La cursiva es mía.
} 
Doria, así como su estrategia para la conservación del poder en el ámbito local. Luna agregaba:

... los diputados de Famatina se formaron arbitrariamente un plan, desconocido en sus mismas ordenanzas, y procedimientos con independencia absoluta de los Magistrados de esta República, con abuso de la limitadísima jurisdicción, que les conceden los art. $2^{\circ}$ y $3^{\circ}$ de las mismas ordenanzas con respecto al mineral, sujetaron a los mineros en todas sus causas, sean o no minerales, prohibiendo a los jueces del territorio su privativo conocimiento. ${ }^{67}$

Inicialmente los diputados territoriales eran dos, Francisco-Xavier Brizuela y Doria y Manuel Derqui, tal como lo indicaba la Ordenanza de 1783, (Martiré, 196) aunque en este caso no aparecen integrados en una jurisdicción Real de Minas sino, más bien, a esa novedosa demarcación independiente de la ciudad de La Rioja. De esta manera Luna describe la diputación:

\begin{abstract}
Ellos [por los diputados] han publicado su bando de gobernación universal, y han practicado la tasación de abastos, y salarios, sin audiencia, ni concurso de los interesados, y con manifiesta usurpación de la jurisdicción ordinaria, de los Magistrados de esta República, y en que principalmente utilizan los Diputados, y sus parientes, únicos inmediatos asendados de aquel mineral. ${ }^{68}$
\end{abstract}

Así parece que la creación de la Diputación territorial sirvió a los Brizuela y Doria, y a sus allegados, para garantizarse un poder más grande sobre el partido de Famatina, implicando además la administración del mineral. La Diputación territorial de Minas, sin haber sido la única de su género en la región, aparece como la definió Luna: un «plan desconocido» y «sin exemplar». Un proyecto desconocido, sobre todo, por el alcance que se intentó dar a la jurisdicción y por las medidas que se habrían tomado para administrarla.

Pese a que la Diputación de Famatina no parece haber funcionado durante mucho tiempo, ni haberse sujetado a una reglamentación clara, constituyó una estrategia de construcción e implantación de poder a nivel local. Para los Brizuela y Doria, quienes habían visto disminuido su influjo con la llegada de Luna a la subdelegación de La Rioja, la Diputación fue una oportunidad de reafirmase. La

\footnotetext{
${ }^{67}$ AGN, X-21-1-9, 17 de agosto de 1812, documento producido por el Teniente Gobernador Luna. El resaltado me pertenece Es interesante destacar que en 1810 Caballero había subrayado como «urgentísima la necesidad de formar un código simplificado (...). El de Toledo es muy complicado, y el de México, tiene relación con los principios que lo motivaron. Pero de este último pueden, y deben sacar trozos enteros para formar el especial que debe regir la minería del mando de V.E.» José María Caballero, Anguinán [Famatina] 18 de septiembre de 1810, en AGN X 2-3-13.

${ }^{68}$ AGN, X-21-1-9,
} 
instalación de una «nueva e independiente República» no habría parecido tan descabellada a unos hacendados que tenían dentro de sus representaciones del poder a la ciudad estado, la República, como forma legítima y legitimante de administración.

\section{La independencia de 1815}

La frustrada viabilidad de la diputación territorial produjo un deterioro aún mayor de los términos de la convivencia política local y el tono de las disputas entre los distintos sectores aumentó a medida que pasaba el tiempo. Sin abandonar la idea de hacerse con el gobierno, los Brizuela y Doria intentaron anular al Teniente Gobernador Luna. Según las palabras de este último:

Es incalculable cuanto han trabajado los cuatro individuos que componen este débil Cabildo en buscar medios y arbitrios para incomodarme; pero a pesar de este interesante empeño jamás podrán justificar de mi individuo una sola partícula contra mi comportación en el justo desempeño de mi ministerio. ${ }^{69}$

Seguramente para aquietar las revueltas aguas de la política riojana el poder central decidió el 19 de diciembre de 1813, luego de meses enteros de cartas incriminatorias de uno y otro bando, designar a Francisco Pantaleón Luna como Teniente Gobernador de San Juan sacándolo claramente de la escena política local, aunque no de la regional. ${ }^{70}$ Durante los meses que transcurrieron entre su designación y su muerte acaecida el 6 de julio de 1814, Luna permanece en La Rioja, empecinado - pese a su quebrantada salud - en la guerra que tenía abierta con los Brizuela y Doria.

Durante el mes de junio de 1813, la tensión iba in crescendo y ante la perspectiva de un nuevo gobierno representado por la Asamblea de 1813, ambos sectores abrigaron esperanzas de ganar sus apuestas. El 19 de junio habiendo alcanzado el máximo grado de conflictividad, Luna escribía uno de sus largos, prolijos, detallados y adjetivados informes sobre la política local distribuyendo entre los Rodríguez, los Brizuela y Doria y sus allegados, las culpas del estado

\footnotetext{
${ }^{69}$ AGN, X-5-6-5, comunicación de Luna del 3 de enero de 1813.

${ }^{70}$ En una carta del 25 de junio de 1814, el Cabildo informa al gobierno central: «... presumimos que esta suspensión [se refiere a la de Luna] ocasionó la grave enfermedad que hasta la fecha de este se halla postrado en cama desahuciado del facultativo de esta ciudad...», AGN, X-5-6-5. Luna moría el 6 de julio de 1814. Avisa su muerte Francisco Xavier Brizuela y Dávila, Teniente Gobernador reemplazante de Luna, AGN, X-5-6-5.
} 
lamentable de la política riojana y decía: «quedará esta República sugeta a las intrigas, intereses y despotismo de la única familia de Chilecito y Rodríguez [se refiere a los Rodríguez de Córdoba], que es una misma, y trae su ascendente antiguo desde el mismo Córdoba». ${ }^{71} \mathrm{El}$ texto es especialmente interesante porque menciona, una vez más, el origen del vínculo entre las familias que luego actuaron mancomunadamente fundando una «República a expectación del famoso cerro de Famatina, comprendido en su inmediato territorio».

La tensión parece ceder ante la presencia del Obispo de la diócesis de Córdoba, Rodrigo de Orellana, a la que estaba sujeta La Rioja. El prelado, que se encontraba en visita pastoral, intentó subsanar las dificultades entre las dos facciones y el 25 de junio los individuos del Cabildo - miembros de la Casa de los Brizuela y Doria - y el Teniente Gobernador Luna firmaban un acuerdo en el que se decía: «hemos decidido sellar con un olvido eterno todos los antecedentes que motivaron los recíprocos informes que se han dirigido a esa Superioridad» y se lee en el acta capitular «hemos decidido cortar, a insinuaciones repetidas del Ilustrísimo Señor Obispo de esta Diócesis, que con Pastoral celo se ha interesado sobremanera en la Paz publica de este pueblo, todas las disensiones, y etiquetas políticas...». ${ }^{72}$ Pero, la tregua terminó un año después cuando en mayo de 1814 se retoma con virulencia el intercambio epistolar.

Para el de 3 de mayo, Luna ya no debe ir a San Juan sino a Catamarca, pero se demora en dejar la plaza riojana. Entre los motivos que explican esta dilación arguye que el nuevo destino, Catamarca, es aún más hostil para su salud que La Rioja. ${ }^{73}$ Posiblemente en el ínterin haya logrado que el Gobernador de Córdoba, a la sazón su tío Francisco Antonio Ortiz de Ocampo, interviniera en su favor

\footnotetext{
${ }^{71}$ AGN, X-5-6-5, carta de Luna del 19 de junio de 1813.

${ }^{72}$ AGN, X-5-6-5, Acta del 25 de junio de 1813 y Copia del acta del Cabildo, fojas 60 a 67 del libro de Actas, del 9 de julio de 1813 .

${ }^{73}$ AGN, X-5-6-5, «Mi salida de esta ciudad era de justicia lo verificara, por lo rival que me es su temperamento a la salud, pues en dos años de permanencia, no he gozado de ninguna, y solo se ha convertido mi robusta naturaleza antigua en un esqueleto manifiesto, cuyo testimonio de verdad está a la vista de todo el mundo.»
} 
justificando su permanencia en La Rioja, aunque finalmente se ve obligado a acatar la orden. ${ }^{74}$

La situación del territorio revolucionario había cambiado en 1814, por lo que el gobierno central se vio obligado a tomar decisiones importantes que repercutieron en la organización del territorio que dominaba. La amenaza realista a la jurisdicción salteña y el cambio de estrategia militar para logar el control sobre las Provincias Unidas y la independencia sudamericana, fue una de las causas que explican la creación de dos nuevas gobernaciones que desembraron la de Salta y la de Córdoba: la del Tucumán con cabecera en la ciudad de San Miguel y la de Cuyo con sede en Mendoza donde su Gobernador José de San Martin preparaba el ejército de los Andes. 75

Para Córdoba, como se mencionó, se nombró Gobernador Intendente a Francisco A. Ortiz de Ocampo y se trasladó a Francisco P. Luna a Catamarca poniendo en su reemplazo a Francisco Xavier Brizuela y Doria en la Subdelegación de La Rioja. Como es de imaginar estos cambios generaron resistencias y reacciones violentas que desembocaron en algunos movimientos de Pueblo que impulsaron al poder central a corregir, una vez más, el rumbo político. $^{76}$

El 3 de abril de 1815, en Fontezuelas-Buenos Aires, el director supremo Carlos M. de Alvear fue destituido luego de un levantamiento protagonizado por Ignacio Álvarez Thomas. El movimiento produjo un reposicionamiento de las facciones que se disputaban el poder fortaleciendo a los federalistas que tenían como propósito que Buenos Aires recuperase su calidad de provincia. ${ }^{77}$ La crisis,

\footnotetext{
${ }^{74}$ AGN, X-5-6-5, carta del 12 de mayo de 1814.

${ }^{75}$ Según menciona Bazán los motivos oficiales de la creación de las nuevas Gobernaciones intendencias fueron: «remediar los quebrantos de Salta, como teatro de la guerra» $\mathrm{y}$ «distinguir de algún modo el glorioso pueblo de Tucumán» Cf. BAZÁN, Armando, Historia del noroeste argentino. Buenos Aires: Plusultra,1995, pp. 159-165.

${ }^{76}$ Ver Alejandro Morea, «El Congreso de Tucumán, el movimiento de pueblo de La Rioja y la intervención militar de Alejandro Heredia. ¿Escenas del enfrenamiento entre centralistas y federales en el Interior de las Provincias Unidas?», Anuario del Instituto de Historia Argentina, vol. 16, n. ${ }^{0} 1,2016$

${ }^{77}$ Fabián Herrero, Federalistas de Buenos Aires, Buenos Aires, UNLa, 2009, p. 131.
} 
sin duda, debilitó la dirigencia revolucionaria que vio disminuida su capacidad de intervenir en los asuntos internos de los territorios bajo su influencia.

En el espacio que nos interesa las consecuencias se hicieron sentir pronto. El 17 de abril de 1815 Córdoba declaró su independencia rompiendo su relación de subordinación con el Directorio. El 20, el Gobernador electo Javier Díaz obtuvo de un cuerpo asambleario «las mismas facultades y autoridad en esta provincia que la que tuvo el magistrado que reconocieron las Provincias Unidas del Río de la Plata con el título de director supremo». ${ }^{78}$ Restablecida la soberanía del Pueblo de Córdoba, su Gobernador electo Javier Díaz hizo uso de ella para definir su posición no solo frente al Proyecto de los Pueblos libres liderado por Artigas, sino también faz a la élite revolucionaria en el poder del Directorio. ${ }^{79}$

En mayo, como respuesta a la decisión tomada por la cabecera de la Gobernación de Córdoba, el subdelegado de La Rioja Francisco Xavier Brizuela y Doria reúne «al Pueblo» de la ciudad de La Rioja y declara la independencia:

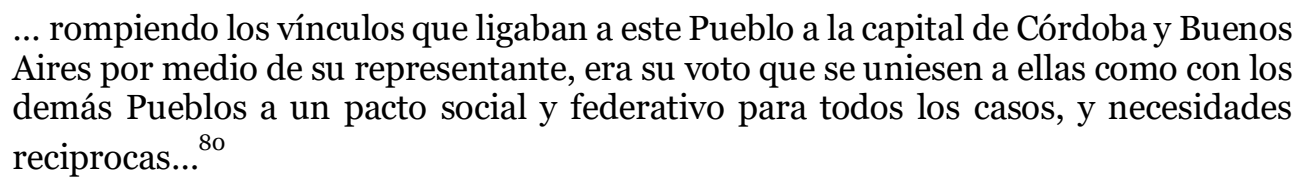

La moción aprobada, aparentemente por unanimidad, dio lugar a la conformación de una «Asamblea permanente» de gobierno creada el 27 de mayo «para que ésta represente en las sesiones sucesivas al presente Congreso [se refiere al Congreso que declaró la independencia de La Rioja], y que sus individuos puedan retirarse a sus atenciones particulares, que esta sea compuesta

\footnotetext{
${ }^{78}$ Carlos Segreti, «La independencia de Córdoba en 1815», Cuarto Congreso Internacional de Historia de América, tomo 2, Buenos Aires, 1966, p. 474.

${ }^{79}$ Ver Valentina Ayrolo, «Los proyectos en el Congreso Constituyente de 1816-1819. La postura de Córdoba en los debates políticos», Bibliographica Americana, Buenos Aires, n. ${ }^{\circ}{ }^{12}$, diciembre, 2016.

${ }^{80}$ AGN, X- 5-6-5, 26 de mayo de 1815. Cabe señalar que el gobernador de Córdoba Javier Díaz consideró desacertada la decisión riojana por considerarla hija de una interpretación errónea sobre su estatuto en el marco de las Provincias. Básicamente Córdoba no le reconoce a La Rioja su carácter de jurisdicción separada de Córdoba de la que dependía desde épocas coloniales. La explicación de ese asunto puede verse en una carta de López a Brizuela del 22 de junio de 1822. Archivo del Obispado de La Rioja, consultado en el AAC, libro de Tama.
} 
por los cuatro vocales del cabildo y tres individuos puramente asambleístas...». ${ }^{81}$ Para los cargos de asambleístas fueron elegidos el cura Francisco Xavier Nicolás Granillo (asociado a los Brizuela y Doria), el padre Guardián Fray Dionisio Tarriga (franciscano) y como secretario Don Baltasar Agüero. ${ }^{82}$ Nótese que los elegidos, además de ser en su mayoría sacerdotes (2/3), cuestión que no sorprende ante la carencia de hombres instruidos, eran individuos que moraban de forma permanente en la ciudad de La Rioja, lugar de residencia administrativa del poder.

El 14 de abril de 1816 un levantamiento armado depone a Brizuela y Doria y por un breve lapso instala a los Villafañe-Ortiz de Ocampo en el poder. El Cabildo dirá que fue «para poner en seguridad su existencia política hecha el juguete de la facción que la oprimía». ${ }^{83}$ Según el Capitán de Húsares José Caparrós, quien se encontraba en La Rioja reclutando soldados para su batallón por orden del poder central, como a las dos de la mañana fue alertado sobre «conmociones en las cercanías del cuartel», preguntando los motivos del levantamiento se le respondió «que cansados de sufrir el yugo de la tiranía habían dado aquel paso para su libertad». ${ }^{84}$ Tan solo cinco días después se informa la elección de Domingo Villafañe como depositario del mando militar y político de la Provincia expresando además su resolución de sujetarse nuevamente a Córdoba por haber considerado al de Brizuela y Doria como un «gobierno intruso». ${ }^{85}$ Los documentos que citamos a continuación corresponden a este momento. El fragmento seleccionado es parte de una larga carta escrita por cuatro notables riojanos al gobierno central con el propósito de informar los

\footnotetext{
${ }^{81}$ Según una carta que le escriben al ejecutivo cordobés uno de los hombres contrarios a Brizuela y Doria Villafañe: «... instalaron una Asamblea de siete vocales inclusive el Cabildo todos miembros de la casa y familia de este Teniente [F-X Brizuela y Doria] hoy titulado Gobernador Supremo Ejecutivo de la Provincia de la Rioja» AHPC, fondo Gobierno, carta de Domingo de Villafañe, 6 de junio de 1815 .

${ }^{82}$ AGN, X- 5-6-5, 27 de abril de 1815.

${ }^{83}$ AGN, X-5-6-5, Acta del Cabildo del 15 de abril de 1815.

${ }^{84}$ Los movimientos y acciones de Caparrós están documentados en: AGN, X-4-1-3, Ejército Auxiliar del Perú.

${ }^{85}$ «... el gobierno intruso de los Brizuela, en este desafortunado Pueblo que le han creído hereditario por el orden de sucesión = Dn. Ramón Brizuela y Doria sucesor de su Padre en el gobierno independiente contra la voluntad general al abrigo de las circunstancias tratando de sostenerse, y hacerse respetar por la fuerza...» AGN, X-5-6-5, 20 de abril de 1816, carta firmada por el Cabildo de La Rioja.
} 
motivos y la forma en que, en 1815, La Rioja se había declarado independiente de Córdoba. En este nuevo relato la independencia aparece ligada a las apetencias de poder de los desplazados:

... para garantir el inicuo proyecto de perpetuarse en el Mando, o más bien de levantar una Dinastía, que fuese trasmisible a su sola familia, antes de realizarse dicha reunión [Brizuela y Doria ] alarmó y municionó toda la tropa [...] así realizada la situación de los concurrentes que preocupados del terror, y del Sobre Salto, que infundía el lúgubre aparato de aquel prospecto servil de la antigua tiranía [...] se produjo el Teniente Gobernador [se refiere a Francisco Xavier Brizuela y Doria] en tono imponente diciendo: que por un acto emanado de la Soberanía de este Pueblo había sido constituido en el Mando...86

Para el presbítero Miguel Calixto del Corro, quien se hallaba en La Rioja recaudando los diezmos de la diócesis, la elección de Brizuela también había sido parte del «ambicioso designio de perpetuarse en el mando, y hacerse Señores de toda la Rioja, los que hasta entonces lo habían sido solo de Zañogasta». ${ }^{87}$

Domingo Villafañe, relata con detalle lo que había ocurrido en ese cabildo abierto que proclamó la independencia de La Rioja. ${ }^{88}$ Según informó al gobierno de Córdoba, fue el propio Francisco Brizuela y Doria quien se impuso en el poder, luego de que Domingo Ocampo con un grupo de aliados, se negara a jurar la independencia de La Rioja por considerar que se había tratado de un ejercicio de presión de los Brizuela:

[Francisco Brizuela y Doria] hizo venir de la campaña a todos sus partidarios y aquellos que había considerado con intento y especialmente a los terrazgueros de su vinculado de Guandacol; y luego que se presentaron en esta a sus órdenes, el 23 de mayo próximo pasado al sol dentro conboco improvisadamente por bando, a la casa consistorial, a toda persona que supiera leer y escribir, para las ocho de la mañana del día siguiente 24 que no podía ser porque la mayor parte de los vecinos viven en sus chacras y labranzas hasta distancias de media legua, como quiera que le

\footnotetext{
${ }^{86}$ AGN, X-5-6-5. El resaltado me pertenece. Carta del 9 de mayo de 1816, firmada por: Mateo de Medina y Sotomayor, Pedro Antonio Peñaloza, Francisco de la Vega y Castro y José Claudio Brizuela. Cabe destacar la presencia de un llanista en la lista de los desplazados del poder: Peñaloza. Este habría sido uno de los primeros representantes de dicho curato en participar de los órganos de la administración riojana. Sobre el asunto ver: Bazán Lazcano, Marcelo, «La sociedad riojana en las postrimerías del virreinato y en la época de la independencia», I Congreso de Historia Argentina y Regional (Tucumán, 1971), Buenos Aires, Academia Nacional de la Historia, 1973.

${ }^{87}$ Se refiere al mayorazgo de San Sebastián de Sañogasta del que Francisco Brizuela y Doria era Señor. AAC, Leg. 20: «Matriculas y padrones», informe dirigido al Gobernador Intendente de Córdoba 4 de enero de 1816, f.400

${ }^{88}$ Los pormenores en la carta citada en texto: AHPC, Gobierno, Caja/tomo 42, 1815. Carta reservada del 6 de junio de 1815, f. 79 .
} 
importaba, porque generalmente es aborrecible su nombre en este Pueblo por su despotismo. ${ }^{89}$

De la larga carta que escribió Villafañe me interesa rescatar cómo, según él, se habría resuelto la elección. Tal como muestra la cita, en la declaración de independencia de 1815 y la inmediata elección de gobernador, no se usó ningún reglamento:

\begin{abstract}
En efecto [Francisco Brizuela y Doria] se benefició la reunión de todos los que estando en la ciudad oyeron el bando, y habiendo depositado a prevención los fusiles en un cuarto contiguo a la sala consistorial y un sargento con cuatro soldados a la puerta, una centinela y dos soldados que cubrían el portón de la calle a las órdenes de su hijo D. Ramón de Briz. ${ }^{a}$ comand.te del Piquete por haberse retirado el Teniente con el mando a su casa a observar mejor de fuera los movimientos del Pueblo con el resto de las tropas. Se principio la votación.

Pero como el cabildo es de su propia casa y gobernaban el teatro además tres hijos y sino hermanos del Teniente [Francisco Brizuela y Doria] y el que tomaba los votos de asiento en asiento era el citado Don Ramón, y a su partido trajeron muchos forasteros sin casa ni ogar, algunos que no sabían leer e incluyeron también dos desertores fue consecuente su reelección en el mando, porque al impulso de tanto semblante amenazado y en medio de la opresión en que nos hallamos sucumbieron los menos cuerdos y cobardes aquanto la función proponía para sostener sus miras ambiciosas... $^{90}$
\end{abstract}

De la lectura de la cita anterior puede pensarse que, aunque desde 1810 para la elite riojana se había hecho evidente que era necesario e importante adecuar el discurso y las prácticas a la nueva política revolucionaria, el cambio no se produjo de inmediato. Como habían escrito los miembros del Cabildo en 1813:

En vano la ilustrada Gazeta llenará de dulces esperanzas a toda América con sus vellas Theorias: En vano los Americanos virtuosos sacrificaran su vida e intereses en obsequio de la livert.d prometida: En vano teñiremos los campos con la preciosa sangre de hermanos Ntros: En vano habremos llamado la atención del Universo con el estruendo de Nxtra libertad civil, mientras los Pueblos no sientan pacticam.te las ventajas del Gov.no libre...91

Aunque en La Rioja las transformaciones hayan sido sobre todo a nivel discursivo, por lo menos hasta la década de 1820, pensamos que la experiencia

\footnotetext{
${ }^{89}$ Las seis carillas de la carta relatan con detalle los acontecimientos trayéndonos el clima que, según Villafañe, reinaba en la ciudad. Así describe como fue la votación: «el Ten.e Gov.r era el prim.o que imponía temor con el imperio de su voz votaba en los actos de reunión para que descubierta su volunt.d ning.o pudiera contra ella con cuya informalidad concluyeron las Actas del 24, 25 y 27 pasado Mayo contentando la independ.a de este Pueblo». AHPC, Gobierno, Caja/tomo 42, 1815. Carta reservada del 6 de junio de 1815, ff. 79-81. El resaltado me pertenece.

${ }^{90}$ AHPC, Gobierno, Caja/tomo 42, 1815. Carta reservada del 6 de junio de 1815, ff. 79-81. El resaltado me pertenece

${ }^{91}$ AGN, X, 5-6-5, Carta del Cabildo de La Rioja, al Gobierno central. 25 de marzo de 1813. El resaltado me pertenece
} 
de esos años permeó la sociedad riojana modificándola. ${ }^{22} \mathrm{El}$ sedimento de esas experiencias políticas de la primera década del siglo enseñó a la elite riojana a manejar con fluidez las redes del poder supra-jurisdiccionales. Instaló de modo progresivo un nuevo lenguaje político y discusiones sobre el origen y la legitimidad del poder, la representación, la ciudadanía, y obligó a reorientar las lealtades, las amistades y los negocios. Podemos pensar que el resultado de este proceso, en parte, fue la aparición de «dirigentes locales más poderosos; esas figuras se destacan ahora de esa unidad que es la familia con más vigor que en tiempos coloniales» como lo menciona Halperin Donghi en Revolución y guerra.

Desde marzo de 1816 estaba reunido en Tucumán un congreso constituyente que el 9 de julio de ese año, declaró la Independencia de las Provincias Unidas en Sud América. Como representante por La Rioja había sido elegido el presbítero Pedro Ignacio de Castro Barros. Su elección no fue acordada por todos y finalmente fue impuesta por los Brizuela y Doria. ${ }^{93}$ Según las fuentes, por influencia de Castro Barros el congreso decidió intervenir La Rioja para deponer a Villafañe. El enviando para tal misión fue el teniente coronel Alejandro Heredia, quien finalmente terminó sometiendo nuevamente la jurisdicción a Ramón Brizuela y Doria. ${ }^{94}$ Ante este panorama, varios cabildantes, 80 vecinos y cincuenta hombres armados dirigidos por Domingo Villafañe abandonaron La Rioja rumbo a Córdoba. El llamado éxodo, implicó la partida de mucha más gente

\footnotetext{
${ }^{92}$ Noemí Goldman, destaca que «... entre 1810 y 1820 la puja por el dominio del poder local entre las familias tradicionales inicia un proceso de ensanchamiento del sentido de la representación política [...] debido a la ampliación de la reglamentación revolucionaria que extiende la representación política - limitada en el inicio de la revolución solo a la ciudad- a toda la jurisdicción». Las cursivas me pertenecen. Goldman, Noemí, «Legalidad y legitimidad en el caudillismo. Juan Facundo Quiroga y La Rioja en el Interior rioplatense (1810-1835)», Boletín del Instituto de Historia Argentina y Americana «Dr. Emilio Ravignani, $3 \cdot{ }^{a}$ Serie, $n .{ }^{\circ} 7$, Buenos Aires, 1993, p. 38.

${ }^{93}$ En la carta escrita al gobierno central por el Cabildo de La Rioja el 20 de abril de 1816, se decía de Castro Barros: «la reunión al Congreso Soberano de un diputado venal que la facción aborrecida constituida en asamblea había nombrado sin intervención, ni expresa facultad del Pueblo, presagiaban la perpetuidad de un gobierno hostil y criminal directamente opuesto a las ideas liberales del sistema de la Patria y a los derechos sagrados de la libertad civil» AGN, X-5-65 .

${ }^{94}$ Sobre este punto ver: Ayrolo, Valentina «Resistencias al Orden. Las formas del poder local en épocas de transición. La Rioja, 1812-1816», en Ana Frega Novales, Maria Medianeira PADOIN, Fábio Kuhn, Maria Celia Bravo e Sonia Rosa Tedeschi (Orgs.), História Regiões e Fronteiras. Santa Maria, Brasil, 2013, Editora: FACOS-UFSM, p. 199- 216 y Morea, Alejandro.
} 
ya que su número iba aumentando a medida que los adherentes a Villafañe que permanecieron en la ciudad de La Rioja, eran encarcelados o perseguidos. ${ }^{95}$

El gobierno de Ramón Brizuela duró hasta diciembre de 1817 cuando La Rioja fue sujetada nuevamente a Córdoba, también ella normalizada, por la intervención del Congreso. ${ }^{96}$

\section{Palabras finales}

Hace más de una década, los estudios sobre el proceso de las Independencias en el mundo hispano abrieron nuevas perspectivas analíticas que permitieron pensar y considerar las experiencias americanas y española, desde una nueva óptica. Ésta consideraba los fundamentos, así como la modalidad que adoptaron en el ejercicio del poder, tanto españoles americanos como peninsulares, mostrando las diferencias regionales. ${ }^{97}$ Una de las conclusiones a las que llegaron las investigaciones mencionadas muestra cómo la coyuntura de desestructuración de la monarquía española dio lugar a la aparición o reaparición, dependiendo el caso, de las aspiraciones soberanas de las ciudades. La vacancia del poder real habría puesto de relieve la persistencia de las concepciones plurales de la soberanía que fueron actuadas por las elites americanas.

\footnotetext{
${ }^{95}$ Uno de los encarcelados fue el presbítero Juan de Dios Villafañe, hermano de Domingo. Las cartas dirigidas por los miembros del Cabildo y por Villafañe en su éxodo hacia Córdoba, en AHPC, Fondo Gobierno, Caja 42, 1815, Legajo «Gobierno de La Rioja». También se encuentran allí las que dirigió Brizuela y Doria al Gobernador de Córdoba. Este episodio es relatado brevemente por Armando Bazán, Historia de La Rioja..., p. 250.

${ }^{96}$ Alejandro Morea "La formación de una región política- militar y la inserción de los oficiales del Ejército Auxiliar del Perú en las Provincias Unidas del Río de la Plata a partir de 1820" Ana Frega Novales, Maria Medianeira Padoin, Fábio Kuhn, María Celia Bravo y Sonia Tedeschi, História Regiões e Fronteiras. Santa Maria, Brasil, Editora: FACOS - UFSM, 2012; p. 217 - 234.

${ }^{97}$ A modo de ejemplo pueden citarse las siguientes obras: Guerra, François-Xavier y Annino, Antonio, Inventando la Nación, Ciudad de México, Fondo de Cultura Económica, 2003, Verdo, Geneviève, «En vísperas del Congreso. La construcción de una identidad política en la Provincias Unidas del Río de la Plata en los años 1815 y 1816», Anuario IEHS, n. ${ }^{\circ}$ 21, 2006, pp. 37-52, María Teresa Calderón y Clément Thibaud, La majestad de los pueblos en la Nueva Granada y Venezuela, 1780-1832. Bogotá, Taurus, 2010; Eric Van Young, La otra rebelión. La lucha por la independencia de México, 1810-1821, Ciudad de México, Fondo de Cultura Económica, 2006 y Federica Morelli, «Entre el antiguo y el nuevo régimen: el triunfo de los cuerpos intermedios. El caso de la Audiencia de Quito, 1765-1830", Historia y política: Ideas, procesos y movimientos sociales, n. ${ }^{\circ} 10,2003$, pp. 163-189.
} 
Como decíamos, los análisis historiográficos enfatizaron en estas cuestiones centrales para entender los procesos de independencias desandando tanta historia nacional. Pero, en el camino se perdió de vista que esas experiencias políticas llamadas locales, ${ }^{98}$ constituyeron las formas esenciales y fundantes de la vida política americana y fueron las que permitieron la experimentación y sedimentación de unas prácticas hasta entonces desconocidas. ${ }^{99}$ Estudiar estas experiencias en sí mismas nos permite identificar las concepciones políticas persistentes, las nuevas y las hibridadas, como estructurantes de prácticas políticas novedosas por su carácter, aquellas que F.-X. Guerra invitaba a descubrir para el caso hispano. ${ }^{100}$ Que en algunos casos como el argentino esas experiencias hayan constituido antecedentes de un estado nacional, fue uno de los resultados posibles.

En el presente artículo analizamos la forma en la que se expresó la política riojana en la coyuntura posrevolucionaria, a partir de una lógica que ponía en relación las dinámicas e intereses de las Familias que conformaban la sociedad. Así pudimos ver dos experiencias, la de la Diputación de Minas y la de la independencia local, que muestran formas de ejercer, pensar y elaborar lo político. Pudimos reconocer estas experiencias y sus momentos como parte del proceso de aprendizaje, sedimentación y acomodamiento de las estrategias de gestión del poder local que, podemos suponer, serán importantes para la construcción de la futura entidad provincial.

\section{Fuentes}

-Archivo del Arzobispado de Córdoba, ACC: Leg. 20: «Matriculas y padrones» -Archivo del Obispado de La Rioja (AOLR en el AAC), Libro de Tama

\footnotetext{
${ }^{98}$ Estas ideas fueron desarrolladas por Geneviève Verdo en un texto inédito «Pensar la construcción política fuera del marco nacional». Agradezco a la autora haberme facilitado el escrito.

${ }^{99}$ En este sentido, otra de las virtudes del libro de Tulio Halperin Donghi Revolución y guerra fue justamente la de llamar la atención sobre el nacimiento de la política como actividad en sí misma y parte de un proceso que se inicia en el Río de la Plata, con las invasiones inglesas y continua luego.

${ }^{100}$ François-Xavier Guerra, «De la política antigua a la política moderna..., p. 212.
} 
-Archivo General de la Nación (Argentina) AGN: Sala X: 21-9-1, 2-3-12 , 2-3-13, 41-3, 5-6-5, 5-3-5 y Sala IX: 24-3-5

-Archivo Histórico de la Provincia de Córdoba (AHPC): Fondo Gobierno, Cajas/Tomos 31, 32 y 42.

- Colección Documental «Mons. Dr. Pablo Cabrera», Sección Americanistas, Biblioteca Central de la Facultad de Filosofía y Humanidades «Elma Kohlmeyer de Estrabou» ex Instituto de Estudios Americanistas, Universidad Nacional de Córdoba (IEA) Documento n. ${ }^{\circ} 3850$.

\section{Bibliografía}

Aranda Pérez, Francisco, «Un reino de repúblicas. Comunidades políticas ciudadano-oligárquicas y su representación en la Castilla Moderna» María Ángeles Faya Díaz (Coord.), Las ciudades españolas en la Edad Moderna: oligarquías urbanas y gobierno municipal, Oviedo, KRK ediciones, 2014, pp. 23-62.

Ayrolo, Valentina, «La ciudad cooptada. Refractarios revolucionarios en Córdoba del Tucumán (1810-1816)» Anuario IEHS, n. ${ }^{\circ}$ 26, 2011, pp. 11-29.

- «"El sabor a soberanos" La experiencia de la diputación territorial de minas como espacio local de poder. Famatina, La Rioja del Tucumán, 1812» Secuencia, Ciudad de México, Instituto Mora, n. ${ }^{\circ}$ 86, mayo-agosto, 2013, pp. 53-74.

- «Hacia la construcción de las Provincias: vínculos y obligaciones de Pueblo a Pueblo. Los casos de Córdoba y La Rioja 1815-1824", Revista de Historia del Derecho, Instituto de Investigaciones de Historia del Derecho, n. ${ }^{\circ} 52$, julio-diciembre 2016, pp. 1-30.

- «Los proyectos en el Congreso Constituyente de 1816-1819. La postura de Córdoba en los debates políticos», Bibliographica Americana, Buenos Aires, $n .^{\circ}$ 12, diciembre, 2016.

- «Resistencias al Orden. Las formas del poder local en épocas de transición. La Rioja, 1812-1816», en Ana FREGA NOVALES, Maria Medianeira PADOIN, Fábio KUHN, Maria Celia BRAVO e Sonia Rosa TEDESCHI (Orgs.), História Regiões e Fronteiras. Santa Maria, Brasil, 2013, Editora: FACOSUFSM, p. 199-216.

Bazán Lascano, Marcelo, «La sociedad riojana en las postrimerías del virreinato y en la época de la independencia», I Congreso de Historia Argentina y Regional (Tucumán, 1971), Buenos Aires, Academia Nacional de la Historia, 1973.

Bazán , Armando, Historia de La Rioja. Buenos Aires: Plusultra, 1979, pp. 267272.

- Historia del noroeste argentino. Buenos Aires: Plusultra, 1995.

Boixados, Roxana, «Familia, herencia e identidad. Las estrategias de reproducción de la elite en La Rioja colonial (gobernación del Tucumán, siglo XVII y principios del XVIII)». Revista de la Asociación de Demografía Histórica. Madrid. ADEH, 2001, pp. 147-181 
- «Herencia, descendencia y patrimonio en La Rioja colonial». Andes, Antropología e Historia, n. ${ }^{\circ}$ 8. Cepiha. Universidad Nacional de Salta, 1997, pp. 199-223.

Brading, David, Mineros y Comerciantes en el México borbónico (1763-1810), Ciudad de México, Fondo de Cultura Económica, [1971] 1983.

Caillet-Bois, Ricardo «Introducción» Archivo del Brigadier General Juan Facundo Quiroga, Tomo I, Buenos Aires,Universidad de Buenos Aires, 1957.

Calderón, María Teresa y Thibaud, Clément, La majestad de los pueblos en la Nueva Granada y Venezuela, 1780-1832, Bogotá, Taurus, 2010.

Cansanello, Oreste Carlos, «De súbditos a ciudadanos. Los pobladores rurales bonaerenses entre el Antiguo Régimen y la Modernidad», Boletín del Instituto de Historia Argentina y Americana «Dr. Emilio Ravignani», 1995, vol. 11, p. 113-140.

De la Vega Díaz, Dardo, «La Rioja (1810-1862)» Historia de la Nación Argentina, Tomo X, Buenos Aires, 1947.

Dougnac Rodríguez, Antonio, «Proyección de las ordenanzas de minería de nueva España en Chile (1787-1874)», Revista de Estudios Histórico-Jurídicos, n. ${ }^{\circ} 21,1999$, pp. 111-158.

Enciso Contreras, José, «La diputación de minas en Zacatecas en el siglo XVI», Memoria del X Congreso del Instituto Internacional de Historia del Derecho Indiano, Ciudad de México: Universidad Nacional Autónoma de México, 1995.

Gavira Márquez, María Concepción, «Disciplina laboral y códigos mineros en los virreinatos del Río de la Plata y Nueva España a fines del periodo colonial», Relaciones, año XXVI, n. ${ }^{\circ}$ 102, Colegio de Michoacán, Zamora, 2005, pp. 201-232.

Goldman, Noemí, «Legalidad y legitimidad en el caudillismo. Juan Facundo Quiroga y La Rioja en el Interior rioplatense (1810-1835)», Boletín del Instituto de Historia Argentina y Americana «Dr. Emilio Ravignani, $3 .^{\text {a }}$ Serie, . $^{\circ}$ 7, Buenos Aires, 1993, pp. 29-58.

Guerra, François-Xavier, «Hacia una nueva historia política: actores sociales y actores políticos», Anuario IEHS, 1989, n. $^{\circ} 4$, pp. 243-284.

Guerra, François-Xavier, «De la política antigua a la política moderna: algunas proposiciones», Anuario IHES, 2003, n. ${ }^{\circ}$ 18, pp. 201-212.

- Modernidad e independencias. Ciudad de México, Fondo de Cultura Económica, 2014 (Mapfre, 1992) p. 77.

Guerra, François-Xavier y Annino, Antonio, Inventando la Nación. Ciudad de México, Fondo de Cultura Económica, 2003.

Halperin Donghi, Tulio, De la Revolución de Independencia a la Confederación Rosista. Buenos Aires, Paidós, 1984, pp. 81-83.

Halperín Donghi, Tulio, Revolución y Guerra. Buenos Aires, Fondo de Cultura Económica, 1972, pp. 292-309.

Herrero, Fabián, Federalistas de Buenos Aires, Buenos Aires, UNLa, 2009, p. 131. 
Hespanha, Manuel, Vísperas del Leviatán: instituciones y poder político (Portugal, siglo XVII), Madrid, Taurus, 1989.

Martiré, Eduardo, «La autoridad minera en el código carolino de Pedro Vicente Cañete» Revista Chilena de Historia del Derecho, n. ${ }^{\circ}$ 6, vol. 14, 1970.

Martiré, Eduardo, «La autoridad minera en el código carolino de Pedro Vicente Cañete» Revista Chilena de Historia del Derecho, n. ${ }^{\circ}$ 6, vol. 14, 1970, pp.185-199.

Martiré, Eduardo, Historia del derecho minero argentino, Buenos Aires, Perrot, 1979.

Mercham, Lloyd J., «The Real Minas as a political Institution. A study as a frontier institution in Spanish Colonial America», HAHR, vol.7, n. ${ }^{\mathrm{1}}{ }^{1}$, febrero, 1927, pp. 45-83.

Morea, Alejandro, «El Congreso de Tucumán, el movimiento de pueblo de La Rioja y la intervención militar de Alejandro Heredia. ¿Escenas del enfrenamiento entre centralistas y federales en el Interior de las Provincias Unidas?», Anuario del Instituto de Historia Argentina, vol. 16, n. ${ }^{\circ}$ 1, 2016.

Morelli, Federica, «Entre el antiguo y el nuevo régimen: el triunfo de los cuerpos intermedios. El caso de la Audiencia de Quito, 1765-1830», Historia y Política: Ideas, Procesos y Movimientos Sociales, n. ${ }^{0}$ 10, 2003, pp. 163189.

Ortega Noriega, Sergio, Breve historia de Sinaloa, Ciudad de México, Fondo de Cultura Económica-El Colegio de México, 1999, Fideicomiso Historia de las Américas, «Serie Breves Historias de los Estados de la República», 1999.

Ots Capdequí, José M., Manual de Historia del derecho español en las Indias, Buenos Aires, Losada, 1945.

Palti, Elías, «Orden político y ciudadanía. Debates en el liberalismo argentino del siglo XIX», Estudios interdisciplinarios de América Latina y el Caribe, vol. 5, n. $^{\circ} 2,2017$.

Paz, Gustavo, «El gobierno de los 'conspicuos': familia y poder en Jujuy, 18531875» Hilda Sabato y Alberto Lettieri, La vida política en la Argentina del siglo XIX. Buenos Aires, Fondo de Cultura Económica, 2003.

Reyes, Marcelino, Bosquejo histórico de la Provincia de La Rioja (1548-1867) Buenos Aires, Cattáneo, 1913.

Rosanvallon, Pierre, Por una historia conceptual de lo político. Buenos Aires, Fondo de Cultura Económica, 2003.

Sarmiento, Domingo F., Facundo. Buenos Aires, Losada, 1997 (1848).

Segreti, Carlos, «La independencia de Córdoba en 1815», Cuarto Congreso Internacional de Historia de América, tomo 2, Buenos Aires, 1966.

Van Young, Eric, La otra rebelión. La lucha por la independencia de México, 1810-1821, Ciudad de México, Fondo de Cultura Económica, 2006.

Verdo, Geneviève, «En vísperas del Congreso. La construcción de una identidad política en la Provincias Unidas del Río de la Plata en los años 1815y 1816», Anuario IEHS, n. ${ }^{\circ}$ 21, 2006, pp. 37-52. 